\title{
Kernos
}

Revue internationale et pluridisciplinaire de religion grecque antique

5 | 1992

Varia

\section{Rodney CASTLEDEN, Minoans. Life in Bronze Age Crete}

\section{Ioannis Loucas}

URL : http://journals.openedition.org/kernos/1071

DOI : 10.4000/kernos. 1071

ISSN : 2034-7871

\section{Éditeur}

Centre international d'étude de la religion grecque antique

\section{Édition imprimée}

Date de publication : 1 janvier 1992

ISSN : 0776-3824

\section{Référence électronique}

loannis Loucas, «Rodney CASTLEden, Minoans. Life in Bronze Age Crete », Kernos [En ligne], 5 | 1992, mis en ligne le 19 avril 2011, consulté le 21 septembre 2020. URL : http://journals.openedition.org/kernos/ 1071 ; DOI : https://doi.org/10.4000/kernos.1071 


\section{Notices bibliographiques}

Rodney CASTLEDEN, Minoans. Life in Bronze Age Crete (illustrated by the author), London-New York, Routledge, 1990, 1 vol. $16 \times 24 \mathrm{~cm}, 210 \mathrm{p}$., 20 pl. et 65 fig. dans le texte.

L'ambition de ce livre est de présenter d'une façon à la fois sommaire et scientifique la vie dans la Crète de l'Âge du Bronze. Une des sept parties qui le constituent est consacrée à la vie religieuse (p. 123-157). L'A. y traite avec un esprit de synthèse remarquable, des croyances minoennes, des rituels et des espaces religieux (enclos sacrés, «temples», etc.) ainsi que des coutumes funéraires. Le texte est souvent suivi des illustrations des trouvailles archéologiques. A la fin du volume, le lecteur trouvera trois appendices qui s'avèrent extrêmement précieux pour l'historien des religions : la liste des sanctuaires de grotte, celle des sanctuaires de sommet et celle des enclos sacrés (p. 179182). L'ouvrage comporte aussi un tableau chronologique (p. 183-184), un commentaire des illustrations (p. 185-194), une liste bibliographique (p. 195-200) et un index (p. 201-210).

Ioannis LOUCAS (Athènes)

Lambros COULOUBARITSIS, Mythe et philosophie chez Parménide, 2e éd., Bruxelles, Éd. Ousia, 1990, 1 vol. 14 x 21 cm, 381 p.

En rendant compte, ici même (Kernos, 1, 1988, p. 250-251), de cet ouvrage, nous soulignions l'originalité de l'exégèse qu'il applique au célèbre penseur d'Élée et nous pronostiquions le large intérêt qu'il susciterait. La première édition a de fait été rapidement épuisée et a suscité des réactions nombreuses, le plus souvent favorables. La seconde édition est pourvue d'une nouvelle préface dans laquelle l'A. indique les menues corrections qu'il a apportées : erreurs typographiques, actualisation de quelques notes bibliographiques et amendement de points mineurs. Parménide a suscité ces dernières années plusieurs études importantes. Il faut souhaiter que s'instaure à présent un véritable dialogue entre les spécialistes. 